\title{
32nd ESNR Annual Meeting and 16th Advanced Course September 20-23, 2007 Genoa, Italy
}

\section{Welcome Address}

Dear Friends and Colleagues,

On behalf of the European Society of Neuroradiology, I warmly welcome you to the 32nd Meeting and 16th Advanced Course of the ESNR.

I would like to thank the ESNR for giving me the opportunity to organize this congress, gathering the most renowned authorities in our field, from both within and outside Europe.

The structure of the meeting is not particularly different from the previous ones, but some peculiar features deserve to be commented upon. Firstly, I decided to introduce two "casebased review sessions", conducted by two widely known experts, which I am sure will be stimulating and interesting occasions to basically reproduce, by means of a group discussion, the daily routine. Secondly, I elected to focus the magisterial lectures on a few relatively unusual topics, which however are frequently the cause of problems in the

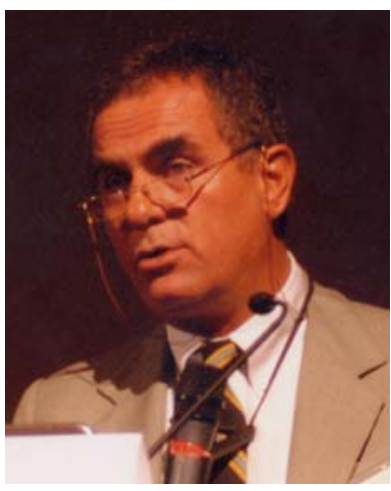
everyday practice. Also, state of the art lectures and refresher courses will be devoted to broader topics whose knowledge has become mandatory to both expert and young neuroradiologists. Parallel sessions and round tables will complete the outline of the congress.

The meeting will also accommodate about 140 proffered papers and a large space for posters on all the various neuroradiological topics, giving everybody plenty of opportunities to bring forth his/her experience and confront with other colleagues. The majority of talks have been assigned to brilliant neuroradiologists belonging to the young and "intermediate" generations, who I believe represent the maximum expression of our cultural growth. Our senior representatives have been asked to moderate and coordinate the sessions with their experience. Hopefully they won't resent me - it is the right, physiological generational turnover!

Coming from pediatric neuroradiology, I decided to choose as the topic for the Advanced Course the pediatric posterior cranial fossa. I think this is a difficult area also for experts in the field and an interesting topic for everyone involved, even though marginally, in imaging children.

I am finally confident that Genoa, with its fascinating atmosphere and surroundings made of a combination of history and marine nature, will provide a stirring backdrop. The meeting will be held in the area of the Old Harbour, called "Porto Antico", which was magnificently restored by the architect Renzo Piano becoming a suggestive area in one of the most beautiful scenarios of the Ligurian Sea. I hope that its fragrance can make your stay even more pleasurable and that the weather will contribute, with a succession of spectacular days as it is typical during this season.

Again, I warmly welcome you all, 